\title{
Cost analysis at different energy sources for heating of an air-supported dome for indoor tennis
}

\author{
Ventsislav Gavrilov ${ }^{1}$, Nina Penkova ${ }^{2, *}$, Penka Zlateva ${ }^{3}$ and Boian Mladenov ${ }^{2}$ \\ ${ }^{1}$ University of Chemical Technology and Metallurgy, Department of Physical Education and Sport, \\ 1756 Sofia, Bulgaria \\ ${ }^{2}$ University of Chemical Technology and Metallurgy, Department of Silicate technology, 1756 \\ Sofia, Bulgaria \\ ${ }^{3}$ Technical University of Varna, Department of Thermal Engineering, 9010 Varna, Bulgaria
}

\begin{abstract}
Numerical analyses of the energy supply for heating of air supported structure for indoor tennis in Sofia via district heating, gas and liquid fuels are performed. The computational procedures are implemented through thermal balances of the structures, calibrated on the base of in situ measurements of the indoor temperature and the amount of the fuel, consumed at heating of an air supported balloon for tennis in University of Chemical technology and Metallurgy. The profitability of the different heating variants is estimated using the price of the energy and the systems.
\end{abstract}

\section{Introduction}

The wholly air-supported structures, also known as air supported domes (ASD), are lower cost alternatives to the traditional building, suitable for covering areas for indoor sports as soccer fields, large swimming pools, tennis and multisport facilities [1,2]. They are mobile and semi-permanent as can be taken down and set up every season. The walls are made by fabric membranes (i.e. PVC coated polyester), anchored to the ground around their perimeter, without needs of supporting beams or columns. The dome access points include revolving doors, pedestrian airlocks for barrier free access, and vehicle airlocks for maintenance and lift equipment.

A higher air pressure inside the dome according to the local meteorological pressure supports the entire structure. This gauge pressure has to compensate the gravity force of the membrane, the wind loads and the snow loads during the winter periods. It is a function of the expected wind speed and snow intensity for the region at a given mass of the envelope. The practice shows that a gauge pressure of $250 \mathrm{~Pa}$ in the indoor space is enough to counteract the loads, mention above [3]. It is maintained by continuous fresh air supply into the structure in order to compensate the leakages and to ensure the necessary fresh air for the people in the dome $[3,4]$.

\footnotetext{
${ }^{*}$ Corresponding author: nina@uctm.edu
} 
The supply airflows are provided by ventilation and heating/cooling units. Their temperature and volumetric flow are regulated by the automation system, based on a differential pressure gauge and temperature sensors. A recirculation of the return air can be maintained in order to prevent inlet temperatures higher than $40{ }^{\circ} \mathrm{C}$. Temperatures above that value are dangerous for the polyester membranes and the people. However, the ventilation system have to ensure $100 \%$ fresh air, if it is necessary. According to [3 and 4] the blower capacity of the ventilation unit should be designed to allow:

- a compensation of the maximal air leakage at the base, around the doors and through the vents. The experience indicates that the leakage losses at a gauge pressure $250 \mathrm{~Pa}$ in the dome can reach $57 \mathrm{~m}^{3} \mathrm{~h}^{-1}$ per linear meter of base perimeter, $340 \mathrm{~m}^{3} \mathrm{~h}^{-1}$ per door assembly, and $43891 \mathrm{x} \mathrm{A} \mathrm{m}^{3} \mathrm{~h}^{-1}$ for vents ( $\mathrm{A}$ is the total vent area in square meters);

- a fresh airflow of at least $60 \mathrm{~m}^{3} \mathrm{~h}^{-1}$ per person according to [5];

- a satisfactory initial inflation time specified by the design requirements.

The temperature and the relative humidity of the indoor air at sport halls have to be in the ranges of $14-16^{\circ} \mathrm{C}$ and $30-60 \%$ respectively, [6]. The optimal air velocity is $0.3-0.4$ $\mathrm{ms}^{-1}$. The Bulgarian regulation [5] imposes more précised parameters for covered sport halls in universities and schools: temperatures of $18{ }^{\circ} \mathrm{C}$ at the winter, $22-27{ }^{\circ} \mathrm{C}$ in the summer. The maintaining of these indoor parameters is connected with relatively high energy needs due to the low thermal resistance of the dome envelopes and the relatively high air exchange rate per hour.

The estimation of the heating and the cooling power at the air supported domes depends on solar gains. They are difficult for computation at the complex geometry of the walls, causing complicated solar ray tracing and infrared radiation heat transfer into the structure [7]. Comprehensive investigations of these related processes have not been published so far. The estimation of the energy needs and the relevant cost analysis at air supported domes are actual and open problems.

This paper presents a cost analysis at different energy sources for heating of an airsupported dome for tennis. The assessments are based on a calibrated thermal balance, based on a model for solar energy gains estimation.

\section{Assessment of the energy inputs and outputs at heating}

\subsection{Object of investigation}

The ASD for indoor tennis cover 3 tennis courts on the territory of University of Chemical Technology and Metallurgy (UCTM) in Sofia (fig. 1 and 2). Parameters of the structure are given in Table 1. The wall area is obtained based on the geometrical model of the construction (fig. 2). It is overestimated with $5 \%$ for the thermal losses computation to reflect the surface relief, obvious from fig. 1.
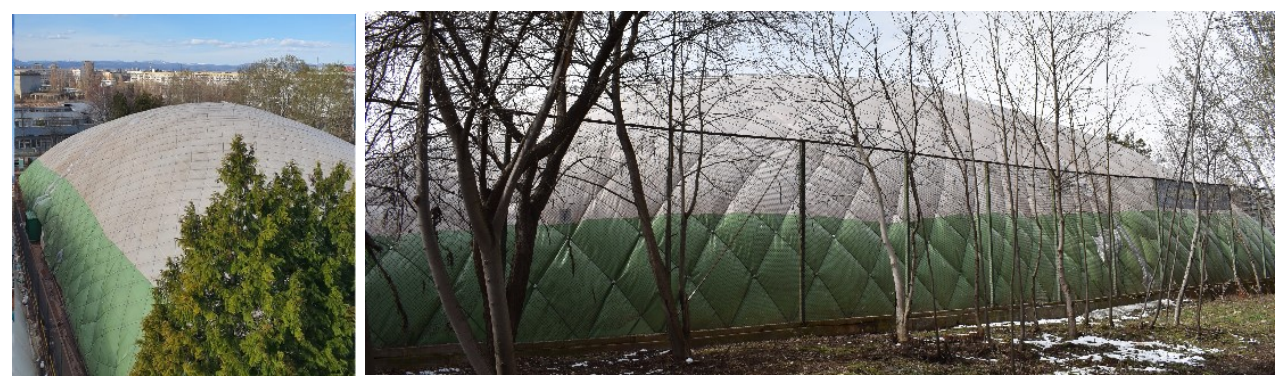

Fig. 1. Air supported dome for indoor tennis at UCTM. 


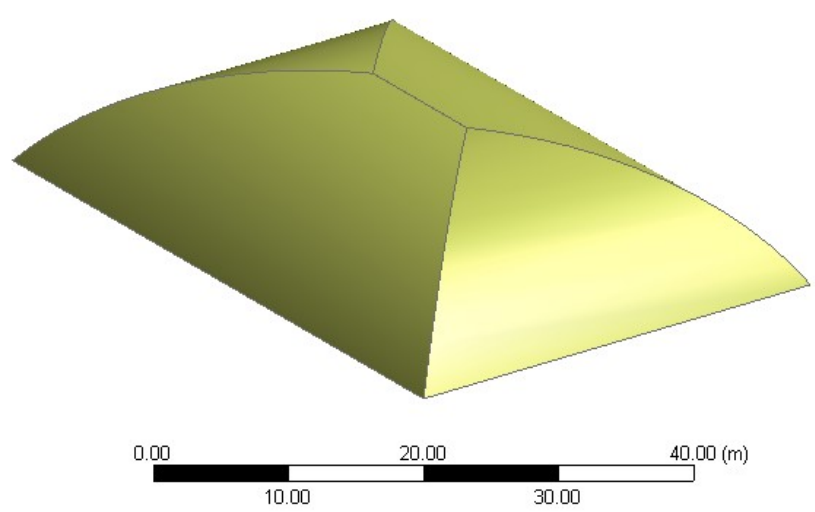

Fig. 2. Geometrical model of ASD.

The air-supported structure is set in the middle of December 2020 with an idea to be taken down in the end of the heating period in Sofia (23 April).

Table 1. Geometrical and thermal parameters of ASD.

\begin{tabular}{|c|c|c|}
\hline Parameter & Dimension & Value \\
\hline Width & $\mathrm{m}$ & 37.10 \\
\hline Length & $\mathrm{m}$ & 48.10 \\
\hline Maximal height & $\mathrm{m}$ & 10 \\
\hline Floor perimeter & $\mathrm{m}$ & 170.40 \\
\hline Floor area, $A_{f}$ & $\mathrm{~m}^{2}$ & 1784.51 \\
\hline Wall area $A_{w}$ & $\mathrm{~m}^{2}$ & 2259.59 \\
\hline Wall area $+5 \%$ & $\mathrm{~m}^{2}$ & 2372.46 \\
\hline Indoor volume $V$ & $\mathrm{~m}^{3}$ & 10424 \\
\hline Supply fresh air flow $\dot{V}$ (over $90 \%$ of the time) & $\mathrm{m}^{3} \mathrm{~h}^{-1}$ & 11400 \\
\hline Air exchange rate per hour (ARCH) & $\mathrm{h}^{-1}$ & 1.09 \\
\hline
\end{tabular}

The ventilation and heating unit (VHU) is type K-140 D, made by Gustav Nolting $\mathrm{GmbH}$. It is consisted of a main blower (volumetric flow $11400 \mathrm{~m}^{3} \mathrm{~h}^{-1}$, gauge pressure 300 $\mathrm{Pa}$, power of $4 \mathrm{~kW}$ ), a stand-by engine (volumetric flow $11000 \mathrm{~m}^{3} \mathrm{~h}^{-1}$ ), and a burner coupled with a heat exchanger for heating of the supply airflow. The stand-by engine is used as a reserve power. The used fuel is diesel oil. The nominal heating capacity of the unit is 181 $\mathrm{kW}$, the nominal heat output is $163 \mathrm{~kW}$ (10\% thermal losses). The burner is switched on during the occupation periods of the ASD. The rest of the time the dome is not heated up only the main blower is working.

There is a possibility for recirculation, but it is not used because of the relatively small capacity of the unit - it support the structure at a lower indoor gauge pressure than recommended. Additional blower with frequency inverter and a maximal power of $15 \mathrm{~kW}$ 
is used to supply additional fresh air in order to keep the gauge pressure at chilly nights and snow loads. The electrical energy consumption of the blowers (minimum $2976 \mathrm{kWh} / \mathrm{month}$ if the additional blower is not working) is not taken into account in the present study. It does not influence on the thermal balance for the heating as the blowers are outside the dome and the heat, released by the engines, is dissipating in the outdoor environmental. In addition, this energy consumption is the same at the different variants of the primary thermal energy.

\subsection{Thermal balance of air supported domes for tennis}

The thermal balance according to the system boundary on figure 3 is:

$$
\dot{Q}_{i n}=\dot{Q}_{w}+\dot{Q}_{f}+\dot{Q}_{l}-\dot{Q}_{s}-\dot{Q}_{h}, \mathrm{~kW}
$$

where $\dot{Q}_{\text {in }}$ is the input heat flow, $\dot{Q}_{w}, \dot{Q}_{f}, \dot{Q}_{l}$ are respectively the thermal losses through the wall, floor and the air leakage, $\dot{Q}_{s}$ represents the solar gains and $\dot{Q}_{h}$ are additional thermal sources (lighting, people, electrical equipment). The last are relatively small at the covered tennis courts and can be neglected.

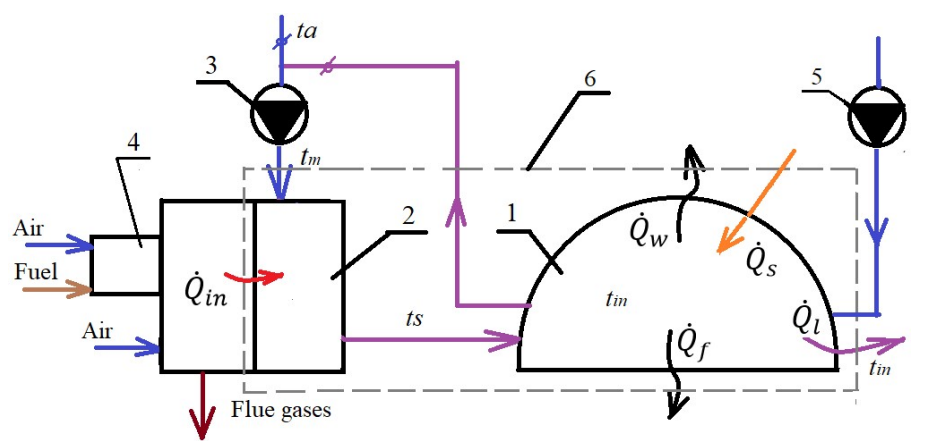

Fig. 2. System, consisted of an air dome for tennis and VHU. 1 - air dome; 2 - heat exchanger of VHU; 3 - main blower of VHU; 4 -burner of VHU; 5- additional brower; 6 - system boundary.

The input heat flow, necessary to heat the supply air with a mass flow $\dot{m}_{l}$ from the ambient temperature $t_{a}$ to temperature $t_{s}$ (fig. 1), is:

$$
\dot{Q}_{\text {in }}=\eta_{g} \dot{Q}_{g}=\dot{m}_{l} c_{\text {air }}\left(t_{s}-t_{a}\right), \mathrm{kW}
$$

where: $\eta_{g}=$ efficiency of the heat generator; $\dot{Q}_{g}=$ the output heat flow of the generator, $\mathrm{kW} ; c_{\text {air }}$ is the specific heat capacity of the air at constant pressure, $\mathrm{kJkg}^{-1} \mathrm{~K}^{-1}$.

At a case of combustion, $\dot{Q}_{g}$ is obtained via the lower heating value LHV $\left[\mathrm{kJkg}^{-1}\right]$ and the mass flow $\dot{B}\left[\mathrm{kgs}^{-1}\right]$ of the fuel:

$$
\dot{Q}_{g}=\dot{B} \cdot L H V, \mathrm{~kW}
$$

The mass flow of the fresh supply air is equal to the mass flow of air leakage. Usually it is higher than the necessary fresh air for the people (maximum 4 per court).

$$
\dot{m}_{l}=\frac{A R C H . V \rho}{3600}
$$


where $\rho=$ air density at the indoor temperature, $\mathrm{kgm}^{-3}$.

The thermal losses through the balloon walls are computed by the equation:

$$
\dot{Q}_{w}=\frac{1.1 U_{w} A_{w}\left(t_{i n}-t_{a}\right)}{1000}, \mathrm{~kW}
$$

where $U_{w}=$ thermal transmittance of the walls, $\mathrm{Wm}^{-2} \mathrm{~K}^{-1}$. It is computed by the thermal resistances of the membrane envelope $R_{m}$, internal and external thermal boundary layers $R_{s i}$ and $R_{s e}$ respectively, $\left[\mathrm{m}^{2} \mathrm{KW}^{-1}\right.$ ]. $U_{w}$ is increased with $10 \%$ in the equation above to reflect the thermal bridges [8].

$$
U_{w}=\frac{1}{R_{s i}+R_{m}+R_{s e}}, \mathrm{Wm}^{-2} \mathrm{~K}^{-1}
$$

The thermal resistance of one layer membrane is:

$$
R_{m}=\frac{\delta_{m}}{K_{m}}, \mathrm{~m}^{2} \mathrm{KW}^{-1}
$$

where $\delta_{m}=$ membrane thickness, $\mathrm{m} ; K_{m}=$ thermal conductivity of the material, $\mathrm{Wm}^{-1} \mathrm{~K}^{-1}$. The heat flow, exchanged with the ground, can be obtained by the equation, used at the floor of greenhouses [9]:

$$
\dot{Q}_{f}=0.001 A_{f}\left[k_{e}\left(t_{i n}-t_{a}\right)-\frac{1.2}{h_{k}}\left(t_{g w}-t_{a}\right)\right], \mathrm{kW}
$$

where $h_{k}=$ underground water depth, $\mathrm{m} ; t_{g w}=$ underground water temperature, ${ }^{\circ} \mathrm{C} ; k_{e}=$ equivalent coefficient of thermal transmittance, $\mathrm{Wm}^{-2} \mathrm{~K}^{-1}$, function of floor area $A_{f}$ and $h_{k}$ [9].

The thermal losses due to the air leakage are computed according to:

$$
\dot{Q}_{l}=\dot{m}_{l} c_{a i r}\left(t_{i n}-t_{a}\right), \mathrm{kW}
$$

The heat flow, expressing solar gains $\dot{Q}_{s}$ in equation (1) is non-zero at the daily time. It is difficult for computation due to the changeable and transient solar incident angle at the curved balloon envelopes (fig. 1 and 2). The polyester membranes are transparent, absorb part of the solar irradiation and have relatively high emissivity in the infrared spectrum [7]. Therefore, the solar heat gains are consisted of the directly transferred solar energy and the absorbed one, which is transferred by convection and radiation in the infrared spectrum to the indoor space. In the present paper the amount of the solar energy, utilized in the dome, is obtained by the monthly energy balance, knowing the fuel consumptions and the other amounts of heats:

$$
Q_{\text {in }}=Q_{w}+Q_{f}+Q_{l}-Q_{s}, \mathrm{kWh} / \mathrm{month}
$$

The input amounts of heat are computed based on the known monthly fuel consumptions $B$ $[\mathrm{kg} / \mathrm{month}]$ :

$$
Q_{\text {in }}=\eta_{g} B \cdot L H V, \mathrm{kWh} / \mathrm{month}
$$


The monthly amounts of heat in the right side of equation (10) are computed with the averaged heat flows $\dot{Q}_{w}^{a v}, \dot{Q}_{f}^{a v}$ and $\dot{Q}_{l}^{a v}$ :

$$
\begin{gathered}
Q_{w}=\tau_{m} \dot{Q}_{w}^{a v}=\tau_{m} \frac{1.1 U_{w} A_{w}\left(t_{i n}^{a v}-t_{a}^{a v}\right)}{1000}, \mathrm{kWh} / \mathrm{month} \\
Q_{f}=\tau_{m} \dot{Q}_{f}^{a v}=0.001 \tau_{m} A_{f}\left[k_{e}\left(t_{i n}^{a v}-t_{a}^{a v}\right)-\frac{1.2}{h_{k}}\left(t_{g w}-t_{a}^{a v}\right)\right], \mathrm{kWh} / \mathrm{month} \\
Q_{l}=\tau_{m} \dot{Q}_{l}^{a v}=\tau_{m} \frac{A R C H . V \rho}{3600} c_{a i r}\left(t_{i n}^{a v}-t_{a}^{a v}\right), \mathrm{kWh} / \mathrm{month}
\end{gathered}
$$

where $\tau_{m}=$ number of the hours of the correspondent month; $t_{a}^{a v}=$ monthly average ambient temperature, ${ }^{\circ} \mathrm{C} ; t_{i n}^{a v}=$ time average indoor temperature, ${ }^{\circ} \mathrm{C}$, computed by the part $d=n / 24$ of the operating hours $n$ per day of the heating system:

$$
t_{i n}^{a v}=d \cdot t_{i n}+(1-d) t_{a}^{a v},{ }^{\circ} \mathrm{C}
$$

The monthly solar gains are accepted as part $\boldsymbol{k}$ of the real sky solar energy $Q_{s, m}$, incident on a horizontal plane with floor area $A_{f}$ :

$$
\begin{array}{r}
Q_{s}=k Q_{s, m}, \mathrm{kWh} / \text { month } \\
Q_{s, m}=q_{s, m} A_{f} D_{m}, \mathrm{kWh} / \text { month }
\end{array}
$$

where $q_{s, m}=$ specific amount of solar energy on a horizontal plane, $\mathrm{kWhm}^{-2} \mathrm{day}^{-1} ; D_{m}=$ number of the days per months at the heating period according to [8].

The coefficient $k$ is obtained by equation (10). This approach is applicable as there is enough information about the solar energy, incident on the horizontal planes [10].

\subsection{Calibration of the thermal balance}

January and February are the first full months of the operation of the ASD. The average ambient temperature for these months, obtained via meteorological database [11] and the established indoor temperature during the time intervals with switched on heating are given in Table 2. The time duration of the heating correspond to the occupation periods that are initially smaller than the predicted one (12h/day) and increase gradually.

Table 2. Indoor and outdoor temperatures.

\begin{tabular}{|c|c|c|c|c|}
\hline Month & $t_{a}^{a v}$ & Heating time & Measured $t_{\text {in }}$ & $t_{\text {in }}^{a v}$ \\
\hline- & ${ }^{\circ} \mathrm{C}$ & $\mathrm{h} /$ day & ${ }^{\circ} \mathrm{C}$ & ${ }^{\circ} \mathrm{C}$ \\
\hline 01.2021 & 1.3 & 6 & 12 & 3.98 \\
\hline 02.2021 & 4.2 & 8 & 15 & 7.80 \\
\hline
\end{tabular}

The daily amounts of the solar energy, incident on a horizontal plane at the location of the tennis courts is obtained by [10] as averaged values for 37 years period (1984-2019). They are used to compute the monthly solar gains in Table 3. The solar gains for January and 
February are used in the energy balance (10) to obtain the part $k$ of the utilized solar energy in the dome (Table 4).

Table 3. Incident solar energy on a horizontal plane

\begin{tabular}{|c|c|c|c|c|c|c|c|}
\hline Month & January & February & March & April & October & November & December \\
\hline $\begin{array}{c}q_{s, m} \\
\mathrm{kWhm}^{-2} \mathrm{day}^{-1}\end{array}$ & 1.706 & 2.476 & 3.414 & 4.263 & 2.840 & 1.801 & 1.448 \\
\hline $\begin{array}{c}D_{m} \\
\text { Days/month }\end{array}$ & 31 & 28 & 31 & 23 & 17 & 30 & 31 \\
\hline $\begin{array}{c}Q_{s, m} \\
\mathrm{kWh} / \text { month }\end{array}$ & 94397 & 123694 & 188886 & 174949 & 86148 & 96393 & 80075 \\
\hline
\end{tabular}

The monthly amounts of heat, participating in the balance, are computed at the established monthly fuel consumptions and the parameters: $L H V=9.7525 \mathrm{kWhl}^{-1} ; R_{S i}=0.1 \mathrm{~m}^{2} \mathrm{KW}^{-1}$; $R_{s e}=0.043 \mathrm{~m}^{2} \mathrm{KW}^{-1} ; \mathrm{U}_{\mathrm{w}}=6.51 \mathrm{Wm}^{-1} \mathrm{~K}^{-1} ; \eta_{g}=0.1 ; k_{e}=0.5 \mathrm{Wm}^{-2} \mathrm{~K}^{-1} ; h_{k}=6 \mathrm{~m} ; t_{g w}=10^{\circ} \mathrm{C}$. It is obvious that the thermal losses through the dome walls are the higher than the other, but they are compensate by the solar energy.

Table 4. Monthly amounts of heats.

\begin{tabular}{|c|c|c|c|c|c|c|c|}
\hline Month & $\begin{array}{c}\text { Diesel } \\
\text { consumption }\end{array}$ & $\boldsymbol{Q}_{\boldsymbol{i n}}$ & $\boldsymbol{Q}_{\boldsymbol{w}}$ & $\boldsymbol{Q}_{\boldsymbol{f}}$ & $\boldsymbol{Q}_{\boldsymbol{l}}$ & $\boldsymbol{k}$ & $\boldsymbol{Q}_{\boldsymbol{s}}=\boldsymbol{k} \boldsymbol{Q}_{s, \boldsymbol{m}}$ \\
\hline- & $1 /$ month & $\mathrm{kWh} / \mathrm{month}$ & $\mathrm{kWh} / \mathrm{month}$ & $\mathrm{kWh} / \mathrm{month}$ & $\mathrm{kWh} / \mathrm{month}$ & - & $\begin{array}{c}\mathrm{kWh} / \mathrm{mont} \\
\mathrm{h}\end{array}$ \\
\hline 01.2021 & 1000 & 8777 & 33830 & -534 & 13561 & 0.345 & 32586 \\
\hline 02.2021 & 1000 & 8777 & 41123 & 767 & 16260 & 0.346 & 42786 \\
\hline & & & & & Average & 0.346 & \\
\hline
\end{tabular}

The average $k=0.346$ is the part of the solar energy, incident on a horizontal plane with floor area $A_{f}$, utilized in the investigated air supported dome. It is used in the next analyses at different energy sources.

\section{Thermal and cost analyses at different energy sources}

The 3-month experience show that the present heating capacity of the existing HBU is not enough to maintain the necessary indoor temperature at negative ambient temperatures. The solution of equation (1) in the absence of sunshine at minimal accepted temperature for Sofia $\left(-16{ }^{\circ} \mathrm{C}\right)$ according to [12] gives a design (maximal) heat flow $Q_{i n}=666.132 \mathrm{~kW}$. It is several times higher according to the existing one. This fact and the established insufficient power of the main blower of VHU impose increasing of the capacity of the installation or a new one at the same or different primary energy.

Three options of energy sources for heating are analyzed: thermal energy from combustion of diesel oil (present variant), natural gas and from cogeneration power plants in Sofia (district heating). The monthly thermal balances are implemented at the average ambient temperatures in 7-th climatic zone (where Sofia is). A time occupation of the dome $12 \mathrm{~h} /$ day and an indoor temperature of 15 are accepted. The necessary input amounts of heat 
are given in Table 6. The negative values of the necessary input energy for April and October show that the solar energy gains are enough to heat the dome to the desired temperature during these months.

Table 5. Technical and financial data at the investigated variants

\begin{tabular}{|c|c|c|c|c|}
\hline Type & $\begin{array}{c}\text { Thermal } \\
\text { losses }\end{array}$ & LHV & $\begin{array}{c}\text { Actual cost } \\
\text { with VAT }\end{array}$ & Additional data \\
\hline- & $\%$ & $\mathrm{kWh} / \mathrm{unit}$ & BGN/unit & - \\
\hline Diesel oil & 10 & $11.75 \mathrm{kWh} / \mathrm{kg}$ & $1.82 \mathrm{BGN} / 1$ & Density: $0.83 \mathrm{~kg} / \mathrm{l}$ \\
\hline Natural gas & 8 & $9.305 \mathrm{kWh} / \mathrm{m}^{3}$ & $1.20 \mathrm{BGN} / \mathrm{m}^{3}$ & $\begin{array}{c}\text { The } \mathrm{m}^{3} \text { are at Normal } \\
\text { physical conditions }\end{array}$ \\
\hline $\begin{array}{c}\text { Thermal energy from } \\
\text { district heating }\end{array}$ & 8 & - & $0.1 \mathrm{BGN} / \mathrm{kWh}$ & $\begin{array}{c}\text { The generator of the VHU } \\
\text { is a heat exchanger }\end{array}$ \\
\hline
\end{tabular}

The primary energy, obtained at the thermal losses at the different generators, fuel consumptions and the subsequent actual financial costs for the period of November to March are systematized in Table 7.

Table 6. Monthly amounts of solar gains and input amounts on heat.

\begin{tabular}{|c|c|c|c|c|}
\hline Month & $\boldsymbol{D}_{\boldsymbol{m}}$ & $t_{a}^{a v}$ & $\boldsymbol{Q}_{\boldsymbol{s}}=\boldsymbol{k} \boldsymbol{Q}_{\boldsymbol{s}, \boldsymbol{m}}$ & $\boldsymbol{Q}_{\boldsymbol{i n}}$ \\
\hline- & day/month & ${ }^{\circ} \mathrm{C}$ & $\mathrm{kWh} / \mathrm{month}$ & $\mathrm{kWh} / \mathrm{month}$ \\
\hline 1 & 31 & -0.4 & 32,619 & 89,317 \\
\hline 2 & 28 & 0.2 & 42,743 & 63,149 \\
\hline 3 & 31 & 4.6 & 65,270 & 17,865 \\
\hline 4 & 23 & 10.4 & 54,408 & $-26,628$ \\
\hline 10 & 17 & 11.2 & 26,792 & $-9,707$ \\
\hline 11 & 30 & 5.1 & 33,309 & 43,326 \\
\hline 12 & 31 & 0.4 & 27,670 & 88,663 \\
\hline
\end{tabular}

Table 7. Necessary energy consumptions and costs.

\begin{tabular}{|c|c|c|c|c|c|c|c|c|}
\hline \multirow{2}{*}{ Month } & \multicolumn{3}{|c|}{ Diesel oil } & \multicolumn{3}{c|}{ Natural gas } & \multicolumn{2}{c|}{ District heating } \\
\cline { 2 - 9 } & $\begin{array}{c}\text { Necessary } \\
\text { amount of } \\
\text { heat } \boldsymbol{Q}_{g}\end{array}$ & $\begin{array}{c}\text { Amount } \\
\text { of fuel }\end{array}$ & $\begin{array}{c}\text { Cost } \\
\text { with } \\
\text { VAT }\end{array}$ & $\begin{array}{c}\text { Necessary } \\
\text { amount of } \\
\text { heat } \boldsymbol{Q}_{g}\end{array}$ & $\begin{array}{c}\text { Amount } \\
\text { of fuel }\end{array}$ & $\begin{array}{c}\text { Cost } \\
\text { with } \\
\text { VAT }\end{array}$ & $\begin{array}{c}\text { Necessary } \\
\text { amount of } \\
\text { heat } \boldsymbol{Q}_{g}\end{array}$ & $\begin{array}{c}\text { Cost } \\
\text { with } \\
\text { VAT }\end{array}$ \\
\hline- & $\mathrm{kWh}$ & $1 / \mathrm{month}$ & $\mathrm{BGN}$ & $\mathrm{kWh}$ & $\mathrm{m} / \mathrm{month}$ & - & $\mathrm{kWh} / \mathrm{month}$ & $\mathrm{BGN}$ \\
\hline 1 & 99,241 & 10176 & 18520 & 97,083 & 10433 & 12520 & 97,083 & 9563 \\
\hline 2 & 71,760 & 7358 & 13392 & 68,640 & 7377 & 8852 & 68,640 & 6762 \\
\hline 3 & 20,301 & 2082 & 3789 & 19,419 & 2087 & 2504 & 19,419 & 1913 \\
\hline
\end{tabular}




\begin{tabular}{|c|c|c|c|c|c|c|c|c|}
\hline 11 & 49,234 & 5048 & 9188 & 47,093 & 5061 & 6073 & 47,093 & 4639 \\
\hline 12 & 100,754 & 10331 & 18803 & 96,373 & 10357 & 12429 & 96,373 & 9494 \\
\hline Sum & $\mathbf{3 4 1 , 2 8 9}$ & $\mathbf{3 4 9 9 5}$ & $\mathbf{6 3 6 9 1}$ & $\mathbf{3 2 8 , 6 0 8}$ & $\mathbf{3 5 3 1 5}$ & $\mathbf{4 2 3 7 8}$ & $\mathbf{3 2 8 , 6 0 8}$ & $\mathbf{3 2 3 7 1}$ \\
\hline
\end{tabular}

The necessary thermal energy at the cases of natural gas and district heating are equal because of the same thermal losses. But their cost is different. The cost of the thermal energy for the heating of the ASD is maximal at the use of a diesel oil. It is approximatively twice in comparison with the heating option at district heating. The financial payback times of the energy costs per heating season at the investigated variants are given in Table 9. The computations are implemented at the assumption for a full occupation of the covered tennis courts $12 \mathrm{~h}$ /day and a cost of $30 \mathrm{BGN}$ with VAT per hour per court.

Table 8. Financial payback time of the energy consumption for heating of ASD

\begin{tabular}{|c|c|c|}
\hline Type & $\begin{array}{c}\text { Payback time of the thermal } \\
\text { energy cost }\end{array}$ & $\begin{array}{c}\text { Payback time of the overall } \\
\text { energy cost }\end{array}$ \\
\hline- & Days per heating period & Days per heating period \\
\hline Diesel oil & 59 & 65 \\
\hline Natural gas & 39 & 54 \\
\hline $\begin{array}{c}\text { Thermal energy from district } \\
\text { heating }\end{array}$ & 30 & 36 \\
\hline
\end{tabular}

If the cost of the electrical energy consumption of the blowers is taken into account (approximatively $30 \mathrm{MWh} /$ year x $200 \mathrm{BGN} / \mathrm{kWh}$ ), the payback time will increase (third column of Table 8).

\section{Conclusions}

The suggested approach for estimation of the solar energy gains at the heating of airsupported domes, based on inverse thermal balance at operating installations, is easy for implementation. It is tested and applied at balance assessment of the thermal energy inputs for heating of a covered tennis courts in Sofia at different energy sources. As results of the case study, it was found that:

- the solar energy cover significant part of the thermal losses at the chilly months and it is enough for the heating of the air dome during April and October;

- the energy supply by the district heating of Sofia is the more cost-effective variant for the heating.

Acknowledgements: This study has been financially supported by the project BG05M2OP001-1.0010008: National Centre of Mechatronics and Clean Technologies, funded by Operational Programme for Science and Education for Smart Growth at EU Funds.

\section{References}

1. https://www.thefarleygroup.com/Products.htm

2. R. Torsing, K. Oosterman, J. Bakker, M. Hinssen, I. Bosveld, T. Huijsmans, Procedia Engineering 147, 2848-853 (2016) 
3. D. A Lutes, CBD-137. Air-supported structures, Canadian Building Digest, (1971)

4. Minimum Standards for Air-Supported Structures, Air Structures Manufacturers and Suppliers Assoc. (1961)

5. Bulgarian regulation № РД-02-20-3 for design, implementation and maintenance of public service buildings in the field of education and science, healthcare, culture and arts (2016)

6. Bulgarian instructions № 34 for the hygiene of sports facilities and equipment (2003)

7. H. Suoa, A. Angelottib, A. Zanelli, Energy and Buildings, 109, 35-46 (2015)

8. Bulgarian regulation № 7 of 2004 on the energy efficiency in buildings (2017)

9. S. Stamov et all, Handbook for heating, ventilation and air conditioning, II part, Tehnika in Bulgarian (1991)

10. https://power.larc.nasa.gov: NASA Prediction Of Worldwide Energy Resources (POWER)

11. https://www.stringmeteo.com

12. Bulgarian regulation № 15 of 28 July 2005 on technical rules and standards for design, construction and operation of sites and facilities for heat generation, transmission and distribution (2016) 